\title{
Computing the Time-Varying Effects of Investor Attention in Islamic Stock Returns
}

\author{
Nabila Jawadi $^{1} \cdot$ Fredj Jawadi $^{2} \cdot$ Abdoulkarim Idi Cheffou $^{3}$
}

Accepted: 16 April 2020 / Published online: 19 May 2020

(c) Springer Science+Business Media, LLC, part of Springer Nature 2020

\begin{abstract}
This paper investigates the relationship between investor attention and the Islamic stock market. In particular, we investigate whether investor attention-measured by Google searches - could help to improve the forecasting of Islamic stock returns. To this end, we used quantile regressions to examine the relationship over the period 2004-2016 in order to capture its evolution during calm and turbulent times. We thus investigated the effect of investor attention not only on the mean, but also for the different quantiles. Our findings highlight two important points. First, the relationship between investor attention and Islamic stock returns exhibits time-variation and nonlinearity as investor attention significantly impacts the dynamics of Islamic returns, but its sign and effect vary per quantile. Second, the usefulness of information provided by investor attention improves the forecasting of future Islamic stock returns.
\end{abstract}

Keywords Investor attention · Islamic stock market · Quantile regression · Out-ofsample forecasting

JEL Classification $\mathrm{C} 22 \cdot \mathrm{G} 15$

\section{Introduction}

From behavioral finance theory, we learn that in addition to their own fundamentals, financial markets may be driven by news, rumors, uncertainty, irrational exuberance, animal spirits, investors' feelings, etc. (Shiller 2015; Akerlof and Shiller 2009). For example, high uncertainty can lead to more anxiety and panic for investors,

Nabila Jawadi

nabila.jawadi@ipag.fr

1 IPAG LAB, IPAG Business School, Paris, France

2 University of Lille, Lille, France

3 ISG Paris Business School, Paris, France 
subsequently creating more volatility on the financial markets (Jawadi et al. 2017). The recent and ongoing risk of the Coronavirus epidemic, for instance, has made investors highly uncertain and anxious, and as a result, the French, German and US stock markets lost over 10\% of their value in the last week of February 2020 and more recently, which are the highest losses since 2008. This recent occurrence illustrates the significant relationship between the stock market and investors' behavior, attention and attitude.

To analyze the linkage between investor sentiment and the stock market, this paper investigates the impact of investor attention on stock return dynamics. In particular, we focus on the Islamic stock market in the US and its interaction with investor attention. Islamic finance emerged as an alternative form of finance in the aftermath of the global finance crisis in 2008. The huge losses experienced by investors resulted in severe criticism of the conventional financial system. This led to an increase in investors' interest in the Islamic stock market since the latter appeared to provide an investment framework that is more social, societal, ethical and less risky than the conventional financial system.

The origins of Islamic finance can be traced back to the 1970s, when it was developed as an investment framework compliant with Shariah law to provide a financial framework that met the investors' faith requirements. The Shariah law regulations are based on specific rules, such as prohibition of interest rates, speculation and uncertainty; the sharing of both profit and loss; and greater transparency (Jawadi et al. 2014). However, investor interest in Islamic finance has mainly been observed in the last decade, especially during the severe downturns in the conventional financial investment markets, in the aftermath of the recent global financial crisis.

The relationship between investor attention and the Islamic stock market is particularly relevant since Islamic finance -at least from a theoretical point of view- has built its ethical investment rules in keeping with the principles of Sharia-compliant investors, while conventional investors or speculators might behave differently, sometimes embracing mispricing activities in order to maximize their profits. Accordingly, and given the presence of heterogeneous investors (Jawadi et al. 2017), investor sentiment could impact the Islamic stock market differently depending on the actors who dominate the market. Indeed, the dynamics of the Islamic stock market may be galvanized in two ways: by pure drivers of conventional stock markets (unethical investors according to Shariah law) or investor attention, corresponding to the stabilizing actions of ethically principled investors.

This paper proposes a new specification per quantile to model the dynamics of Islamic stock returns, taking into account the effects of investor attention. In particular, it enables us to further capture the effects of investor attention and interest in Islamic Finance for lower as well as higher quantiles. This specification has the advantage of capturing further asymmetry, nonlinearity and time-variation in the relationship between investor attention and Islamic stock returns. Further, unlike previous related studies, we proxy investor sentiment with a Google Search index using specific research and interest in the Islamic stock market, and we test its capacity to forecast future Islamic stock returns. Our findings show that investor attention has a significant impact on Islamic returns, and that investor attention helps to drive Islamic stock returns higher. 
The remainder of this paper is structured as follows. Section 2 presents a brief literature survey. We rapidly present the econometric methodology in Sect. 3. The empirical results are discussed in Sect. 4, while Sect. 5 concludes.

\section{Literature}

The three-factor Fama-French (1993) model has frequently been applied to explain the dynamics of stock returns. While this model supplants the CAPM (Capital Asset Pricing Model) to explain stock return dynamics through information about firm size and market-to-book ratio in addition to market risk data (Gaunt 2004), other empirical studies point to the presence of additional factors that might explain the dynamics of stock returns: time-varying investment opportunities (Petkova 2006), firm profitability and investment (Fama and French 2015), investor attention (Tang and Zhu 2017; Nguyen et al. 2019), etc. ${ }^{1}$

Nguyen et al. (2019) investigated the impact of investor attention on the dynamics of stock returns for five emerging countries (Indonesia, Malaysia, Philippines, Thailand and Vietnam) over the period 2009-2016. Using the Google search index to proxy investor attention, the authors showed that investor attention has a negative and significant effect on stock returns for the Philippines, Thailand and Vietnam, suggesting that investors might react more quickly to bad rather than to good news in their investment decisions. According to Calvo, investors in emerging markets are less rational and less informed and their strong interest could thus generate lower stock returns as they may overreact to negative signals.

In the same context, Preis et al. (2013) suggested that Google search changes are an indication of changes in investor attention. They captured the interest of investors and found an association between changes in Google searches and high future returns for Germany. Meanwhile, Bollen et al. (2011) showed that the use of searches on Twitter improved the forecasting of Dow Jones Industrial stock returns. According to Preis et al. (2013), changes in Google searches constitute early warning signs of stock market variations. In the same context, Kim et al. (2019) showed that changes in Google searches do not impact contemporaneous and future abnormal returns but lead to volatility and trading volume. Bekiros et al. (2016) argued that investor sentiment does not help to improve the forecasting of stock returns. Overall, studies on the impact of investor attention and/or sentiment on the conventional stock market are not only scarce but also come to different conclusions.

We identified four recent empirical studies with regard to the impact of investor attention on the Islamic stock market. First, Perez-Liston et al. (2016) investigated the linkage between investor sentiment and Islamic stock returns and found a positive relationship. Second, Aloui et al. (2016), also using a wavelet test, identified a high positive correlation between investor sentiment and Islamic stock returns. Third, Ftiti and Hadhri (2019) also applied time-scale tests to show the utility of information provided by investor sentiment and economic policy uncertainty to forecast Islamic stock returns

\footnotetext{
${ }^{1}$ We focus hereafter on the literature on stock return dynamics related to investor attention.
} 
only in the short and medium-terms. Fourth, Khan et al. (2019) constructed a sentiment index for the Islamic stock index using the information provided by Google search volume and showed its usefulness in improving the predictability of Islamic stock returns.

However, all the above studies inappropriately proxy investor sentiment using the financial stress index or the consumer confidence index, for example, which are principally sentiment-related indexes for conventional finance. Indeed, these proxies do not explicitly capture specific investor attention and interest in Islamic stock funds and investment. In addition, the proxies used in previous studies are impacted more by economic variables than by investor sentiment.

In our paper, we rely on a Google Search index using a lexical category specific to the Islamic stock market, which, unlike previous studies, better captures investor attention and interest in Islamic funds. Changes in this index provide further evidence of changes in Islamic stock market attention and monitoring. In addition, unlike previous related empirical studies, we investigate the relationship between Islamic stock returns and investor attention using Quantile Regressions, enabling us to measure the effect of investor attention on Islamic stock returns not only around the mean but also for higher and lower quantiles.

\section{Econometric Methodology}

We specify the relationship between investor attention and Islamic stock returns, while taking into account the fact that the effect of investor sentiment might differ depending on the state of the business cycle. Accordingly, investor attention on Islamic stock returns may have a nonlinear effect. In order to capture this further nonlinearity, we specify a quantile regression, enabling us to characterize this relationship through several quantiles (Koenker and Hallock 2001). This specification presents the advantage of relating the quantiles with investor attention, which could help explain the dynamics of Islamic stock returns.

Formally, we specify the dynamics of Islamic stock returns, noted $R I S_{\mathrm{t}}$, as follows

$$
R I S_{t}=\Phi_{1} X_{t}+\Phi_{2} I A_{t}+\varepsilon_{t}
$$

where $I A_{t}$ denotes investor attention and $X_{t}$ is a control variable that includes the stock return of the conventional US Dow Jones Industrial. $\Phi_{1} X_{t}+\Phi_{2} I A_{t}$ is the conditional mean of the level of the Islamic stock return and $\varepsilon_{t}$ is the error term.

In practice, we estimate the quantiles of the conditional distribution of Islamic stock returns and, for each quantile, we specify an equation for the conditional quantile of Islamic stock returns, denoted hereafter as $q_{\alpha}\left(R I S_{t} \mid I_{t}\right)$, where $I_{t}$ contains information known at time $t$ and defined as:

$$
q_{\alpha}\left(R I S_{t} \mid I_{t}\right)=\Phi_{1 \alpha} X_{t}+\Phi_{2 \alpha} I A_{t}+u_{t}, \quad \text { where } \alpha \in(0,1)
$$

Equation (2) enables us to estimate a time-varying distribution of Islamic stock returns, which is less restrictive than a standard OLS approach as the slope coefficients $\Phi_{1, \alpha}$ and $\Phi_{2, \alpha}$ can vary by quantiles. In particular, if the effect of investor attention is time-varying and fluctuates with the tail of the Islamic stock return 
distribution, this specification might have a different coefficient in the quantile regression tails from that in the median.

Accordingly, we estimate the parameters $\Phi_{1, \alpha}$ and $\Phi_{2, \alpha}$ by replacing the conventional quadratic loss function with the so-called 'tick' loss function':

$$
L_{\alpha}\left(e_{t+1}\right)=\left(\alpha-1\left\{e_{t+1}<0\right\}\right) e_{t+1}
$$

where $e_{t}=C_{t} \hat{\bar{q}}_{\alpha, t}$ is the forecast error; $\hat{\bar{q}}_{\alpha, t}=q_{\alpha}\left(C_{\mathrm{t}} \mid \Im_{t}\right)$ refers to the conditional quantile forecast computed at time $t$, and $\mathbf{1}\{\cdot\}$ is the indicator function.

\section{Empirical Analysis}

\subsection{Preliminary Results}

Our data include the monthly Islamic stock index (Dow Jones Index) for the US and the investor attention index proxied by a Google search index on the Islamic stock market in the US. Both indexes covered the period January 2004-December 2016. We also used the conventional Dow Jones industrial stock index obtained from Bloomberg as a control variable, as well as the Islamic stock index. This is a particularly appropriate sample selection for analyzing the interaction between investor attention and the Islamic stock market both before and after the recent Global Financial crisis. The Islamic stock index was also obtained from Bloomberg and was set up using the closing daily stock price of the end of the month, while the investor attention index was set up using the number of Google searches carried out in the US with the keyword "Islamic Stock Market". This Google trend index thus captures the level and frequency of investor's attention with regard to the Islamic Stock market.

First, from Fig. 1, we note that the Islamic stock index was negatively impacted by the recent Global Financial Crisis (GFC), but that it evolved around a positive tendency in the aftermath of the GFC, benefitting from the downturn in the conventional stock market in 2008. Otherwise, the market attention index shows more volatility excess during the pre-crisis and the GFC periods, suggesting that investor attention in Islamic stocks rose during the most turbulent times, but stabilized in the last decade. The application of unit root tests shows that the Islamic stock index is integrated of one order (noted I(1)) in the same way as the conventional stock index, while the investor attention series is stationary. To better illustrate the dynamics of these two variables, Fig. 2 reports the means of two variables by season and suggests a time-varying dynamic for both series.

We focus hereafter on the specification of the relationship between investor attention and Islamic stock market returns. Thus, we compute the descriptive statistics for both series and note that while symmetry and normality are rejected for both series,

\footnotetext{
${ }^{2}$ See Koenker and Bassett (1978), Koenker and d'Orey (1994), and Jawadi and Sousa (2014) for more details.
} 
(a)

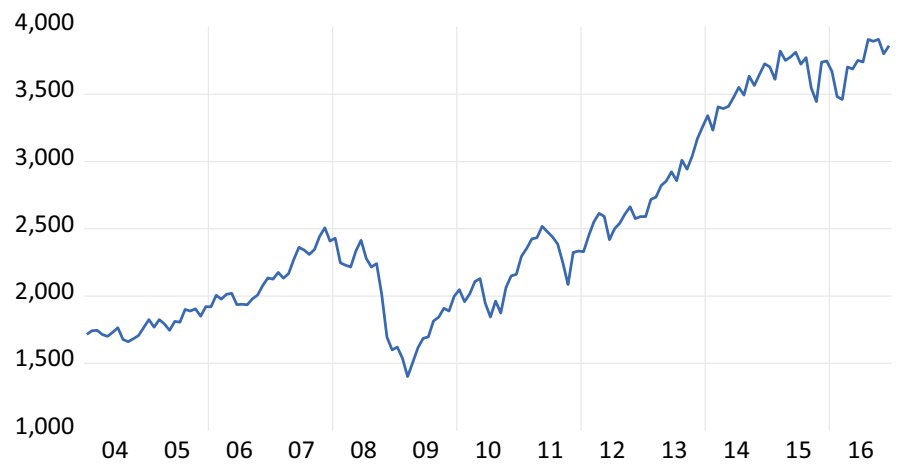

(b)

IAUSISM

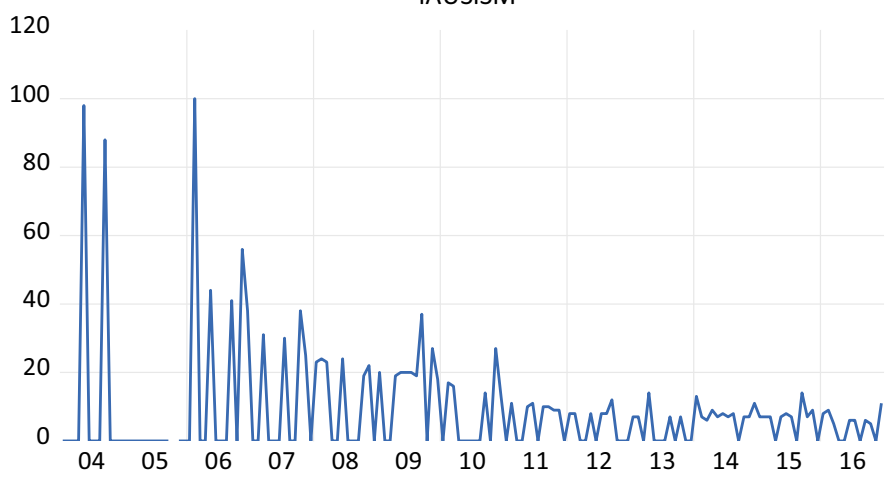

Fig. 1 a The dynamics of the Islamic Dow Jones Stock Index. b The dynamics of investor attention

the investor attention series appears more volatile than the Islamic stock return series. Further, the significant difference between the mean and the median for both variables suggests further evidence of asymmetry in the data.

Next, the analysis of unconditional correlation, reported in Table 1, shows that while the two variables are weakly correlated over the whole period (around 3\%), the linkages between Islamic stock returns and investor attention reached 19\% during the crisis period and $45 \%$ in the aftermath of the bankruptcy of Lehman Borther's bank, suggesting further evidence of a time-varying relationship between investor attention and the Islamic stock market. However, further asymmetrical or nonlinear linkages might escape analysis through the Pearson correlation coefficient analysis.

Second, to better characterize the relationship between the two variables, in Fig. 3 we report the scatter of the two variables. The level of concentration observed in the scatter dynamics suggests that both variables might significantly interact, but that their linkages are not linear.

This result is confirmed when we linearly regress the Islamic stock return on the stock return of conventional stock and investor attention as the latter has no 

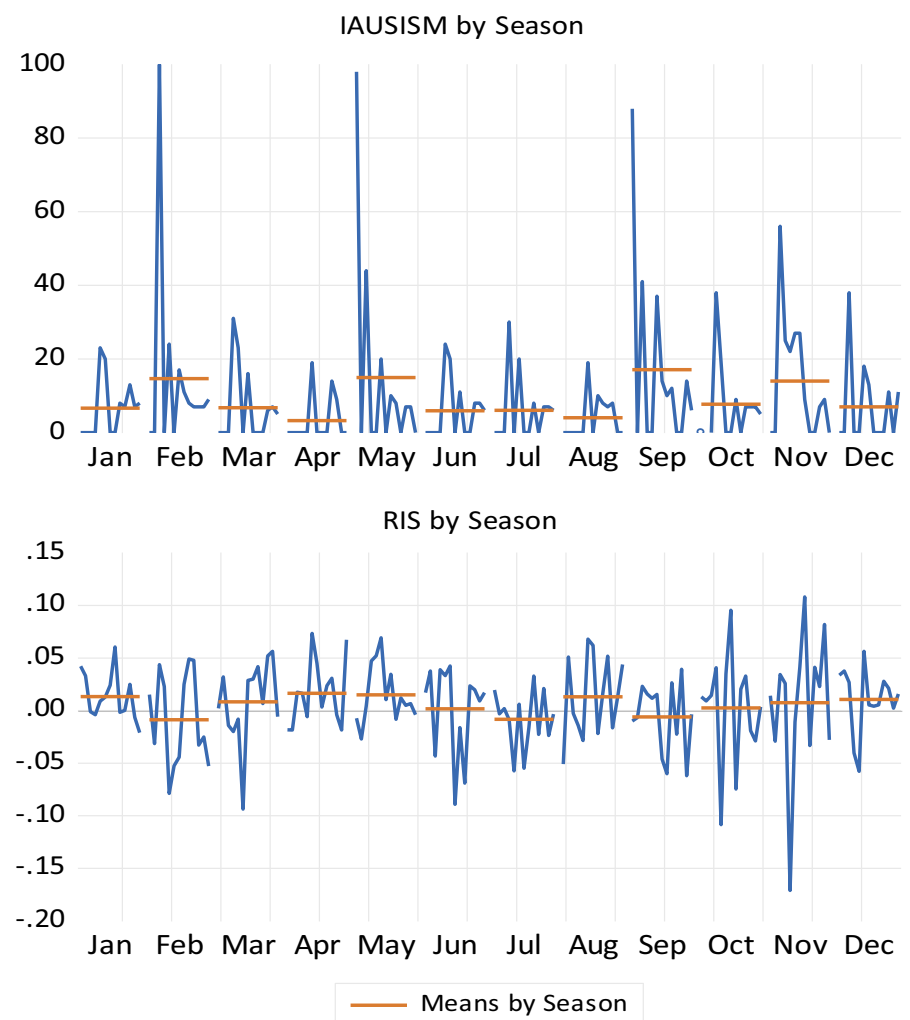

Fig. 2 Dynamics of Islamic stock returns and investor attention by season. Note RIS and IAUSISM denote Islamic stock returns and investor attention respectively

Table 1 Unconditional correlation matrixes

\begin{tabular}{ll}
\hline & $\begin{array}{l}\text { Islamic } \\
\text { stock } \\
\text { returns }\end{array}$ \\
\hline $\begin{array}{l}\text { Full sample: January 2004-December 2016 } \\
\text { Investor attention }\end{array}$ & 0.03 \\
$\begin{array}{l}\text { Sub-sample: December 2005-December 2009 } \\
\text { Investor attention }\end{array}$ & 0.19 \\
\hline
\end{tabular}

significant effect. Indeed, from Table 2, line OLS (1), there is no memory effect in the dynamics of Islamic stock returns and only the US conventional stock return has a positive and significant effect. Next, from the OLS $\left(1^{*}\right)$ line, we note that when we augment Eq. (1) with the associated effect of Investor attention on conventional US stock returns, even though investor attention still remains nonsignificant, the latter interacts with fundamental drivers and reduces the effect of conventional US stock returns on the Islamic one by $4 \%$, in addition to its 
Fig. 3 The linkage between Islamic stock returns and investor attention

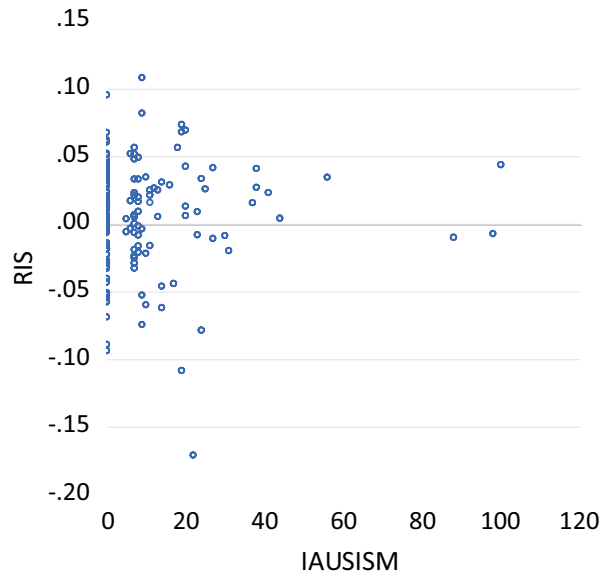

Table 2 Linear modeling results

\begin{tabular}{lllllll}
\hline Variable constant & $\mathrm{R}_{\mathrm{t}}$ & $\mathrm{RIS}_{\mathrm{t}-1}$ & $\mathrm{IA}_{\mathrm{t}}$ & $\mathrm{IA}_{\mathrm{t}}{ }^{*} \mathrm{R}_{\mathrm{t}}$ & $\mathrm{LL}$ & AdjustedR $^{2}$ \\
\hline OLS (1) 0.001 & $0.977^{* * *}$ & 0.011 & $3.0410^{-5}$ & - & 435.08 & 0.871 \\
$(0.963)$ & $(20.54)$ & $(0.384)$ & $(0.370)$ & & & \\
OLS $\left(1^{*}\right) 0.001$ & $0.934^{* * *}$ & 0.005 & $4.0210^{-6}$ & 0.005 & 436.63 & 0.874 \\
$(1.152)$ & $(15.41)$ & $(0.190)$ & $(0.051)$ & $(0.004)$ & &
\end{tabular}

OLS (1) corresponds to the Eq. (1) estimated by the OLS. OLS $(1 *)$ corresponds to the estimation of Eq. (1) augmented by the variable $\mathrm{IA}_{\mathrm{t}} * \mathrm{R}_{\mathrm{t}}$. Values in (.) denote the t-ratios of the estimators with HAC standard errors and covariances obtained by Bartlett Kernel and Newey-West fixed bandwidth =5.0)

LL refers to the statistics of the Log Likelihood function

$* * *, * *, *$ Estimators statically significant at the $10 \%, 5 \%$ and $1 \%$ level, respectively

statistical significance. This suggests that higher investor attention to Islamic stock returns weakens the effect of the conventional financial system.

Next, in order to characterize the effect of investor attention on Islamic stock returns, we investigate their relationship per quantile. We report the main results in Table 3 and note the various interesting findings. First, investor attention has a negative and significant effect on the low quantiles of Islamic stock returns, suggesting that for lower quantiles, investors are more impacted by bad news than by good news, although the higher the quantile, the lower the effect of investor attention. The memory effect in the dynamics of Islamic stock returns is negative and significant only for the quantile $2.5 \%$. The effect of the conventional stock market is positive and significant, however, and higher than that of market attention. Further, when combining the impact of market attention with that of the conventional stock market, the effect on Islamic stock returns is positive, suggesting that for lower quantiles, Islamic stock returns are driven more by fundamentals through the effect of the conventional stock market than by market attention. Second, when looking at the relationship between investor attention and Islamic stock returns around the median, there is no evidence of a significant effect of investor 
Table 3 Quantile regression results

\begin{tabular}{|c|c|c|c|c|c|c|}
\hline Quantile & $\mathrm{R}_{\mathrm{t}}$ & $\mathrm{RIS}_{\mathrm{t}-1}$ & $\mathrm{IA}_{\mathrm{t}}$ & $\mathrm{IA}_{\mathrm{t}} * \mathrm{R}_{\mathrm{t}}$ & WT ( $p$ value) & AdjustedR $^{2}$ \\
\hline $2.5 \%$ & $\begin{array}{l}0.943 * * * \\
(28.40)\end{array}$ & $\begin{array}{l}-0.078 * * * \\
(-3.24)\end{array}$ & $\begin{array}{l}-0.002 * * * * \\
(-4.06)\end{array}$ & $\begin{array}{l}0.015 \text { *** } \\
(2.56)\end{array}$ & 0.09 & 0.15 \\
\hline $25 \%$ & $\begin{array}{l}0.938^{* * * *} \\
(15.93)\end{array}$ & $\begin{array}{l}-0.018 \\
(-0.599)\end{array}$ & $\begin{array}{l}-0.001 * \\
(-1.73)\end{array}$ & $\begin{array}{l}0.006^{*} \\
(1.68)\end{array}$ & 0.05 & 0.64 \\
\hline $50 \%$ & $\begin{array}{l}0.984 * * * \\
(17.73)\end{array}$ & $\begin{array}{l}-0.028 \\
(-0.755)\end{array}$ & $\begin{array}{l}5.33 * 10^{-5} \\
(0.569)\end{array}$ & $\begin{array}{l}0.0002 \\
(0.07)\end{array}$ & 0.05 & 0.63 \\
\hline $75 \%$ & $\begin{array}{l}1.032 * * * \\
(19.47)\end{array}$ & $\begin{array}{l}0.008 \\
(0.297)\end{array}$ & $\begin{array}{l}0.0004 * * * \\
(2.61)\end{array}$ & $\begin{array}{l}-0.007 \\
(-1.02)\end{array}$ & 0.05 & 0.52 \\
\hline $97.5 \%$ & $\begin{array}{l}0.988^{* * * *} \\
(16.50)\end{array}$ & $\begin{array}{l}0.022 \\
(0.767)\end{array}$ & $\begin{array}{l}0.002^{* * * *} \\
(4.66)\end{array}$ & $\begin{array}{l}0.002 \\
(0.129)\end{array}$ & 0.00 & 0.76 \\
\hline $\begin{array}{l}\text { Koenker and } \\
\text { Xiao (2002) test } \\
(p \text {-value })\end{array}$ & $\begin{array}{l}0.00 * * * \\
0.00 * * *\end{array}$ & & & & & \\
\hline $\begin{array}{c}\text { Khmaladze (1981) } \\
\text { test (p-value) }\end{array}$ & & & & & & \\
\hline
\end{tabular}

WT denotes the Wald test which is a Symmetric Quantile Test. The Khmaladze (1981) and Koenker and Xiao (2002) test computes a joint test for which the covariate effects satisfy the null hypothesis of equality of the slope coefficients across quantiles

***, **, *Statically significant at the $10 \%, 5 \%$ and $1 \%$ level, respectively

attention. Third, for higher quantiles of Islamic stock return distribution, investor attention has a positive and significant impact, suggesting that for higher quantiles, investor attention, strengthened by good and positive news, might stimulate the level of Islamic stock returns.

To check the robustness of our results, we applied the Wald test and rejected the hypothesis of symmetry across quantiles. Further, using Khmaladze (1981) and Koenker and Xiao (2002)'s test, we show that the slope coefficients vary across quantiles. These findings confirm the suitability of our specification and validate the assumption of the presence of a time-varying investor attention effect. Indeed, the latter enters the dynamics of Islamic stock returns differently, while remaining negative for lower quantiles and positive for higher quantiles of Islamic stock return distribution.

Finally, we check whether the use of information provided by investor attention could help to improve forecasting of future dynamics of Islamic stock returns. We carried out an out-of-forecasting test over the forecasting period January 2013-December 2016. We report the main results in Fig. 4. Our findings show the usefulness of information provided by investor attention to improve the forecasting of future Islamic stock returns. In particular, the forecasting provided by quantile regressions supplants the linear OLS regression forecast (Eq. 1). 


\section{(a) For quantile $2.5 \%$}

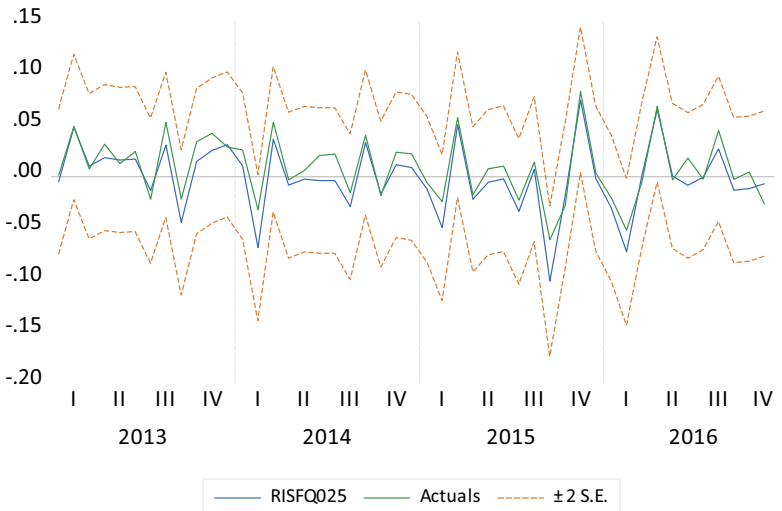

(b) For quantile 25\%

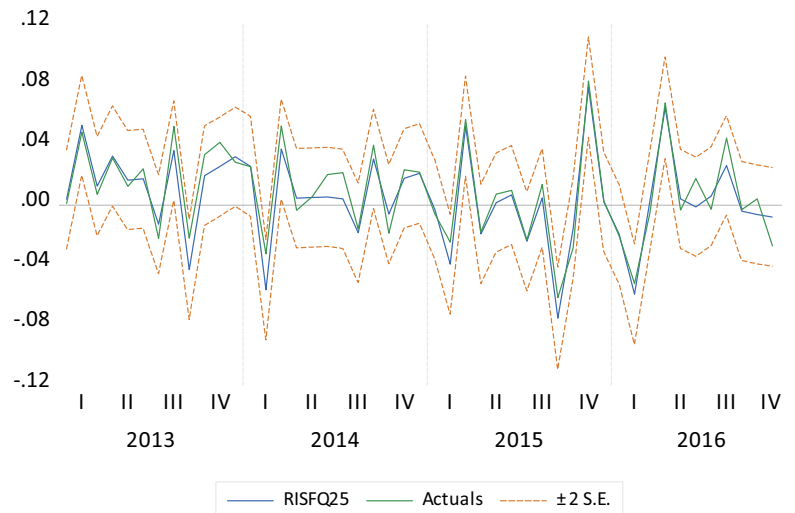

(c) For quantile 50\%

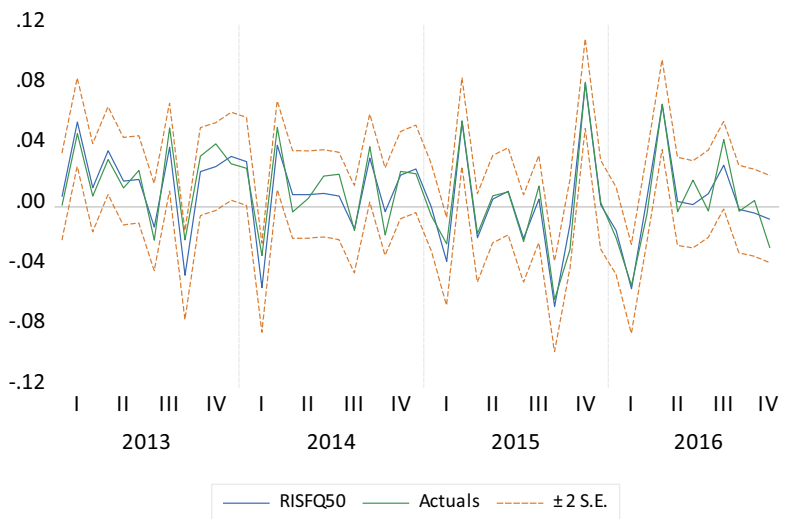

\begin{tabular}{|c|c|}
\hline \multicolumn{2}{|l|}{ Forecast: RISFQ025 } \\
\hline \multicolumn{2}{|l|}{ Actual: RIS } \\
\hline \multicolumn{2}{|c|}{ Forecast sample: 2013M01 2016M12 } \\
\hline \multicolumn{2}{|c|}{ Adjusted sample: 2013M01 2016M11 } \\
\hline \multicolumn{2}{|l|}{ Included observations: 47} \\
\hline Root Mean Squared Error & 0.015399 \\
\hline \multicolumn{2}{|c|}{ Mean Absolute Error $\quad 0.012532$} \\
\hline Mean Abs. Percent Error & 132.2332 \\
\hline \multicolumn{2}{|c|}{ Theil Inequality Coef. 0.237884} \\
\hline \multicolumn{2}{|l|}{ Bias Proportion } \\
\hline Variance Proportion & 0.027020 \\
\hline Covariance Proportion & 0.554038 \\
\hline Theil U2 Coefficient & 0.078105 \\
\hline Symmetric MAPE & 619 \\
\hline
\end{tabular}

\section{Forecast: RISFQ025}

Adjusted sample: 2013M01 2016M11

included observations: 47

Mean Absolute Error 0.012532

Mean Abs. Percent Error $\quad 132.2332$

Theil Inequality Coef. 0.237884

Bias Proportion $\quad 0.418941$

Variance Proportion $\quad 0.027020$

Theil U2 Coefficient $\quad 0.078105$

Symmetric MAPE $\quad 84.69619$
Forecast: RISFQ25

Actual: RIS

Forecast sample: 2013M01 2016M12

Adjusted sample: 2013M01 2016M11

Included observations: 47

Root Mean Squared Error $\quad 0.010535$

Mean Absolute Error 0.008351

Mean Abs. Percent Error $\quad 79.23790$

Theil Inequality Coef. 0.169889

Bias Proportion $\quad 0.113394$

Variance Proportion $\quad 0.002203$

Covariance Proportion $\quad 0.884403$

Theil U2 Coefficient

0.110415

Symmetric MAPE $\quad 64.72641$

Forecast: RISFQ50
Actual: RIS
Forecast sample: 2013M01 2016M12
Adjusted sample: 2013M01 2016M11
Included observations: 47
$\begin{array}{lc}\text { Root Mean Squared Error } & 0.009918 \\ \text { Mean Absolute Error } & 0.007951 \\ \text { Mean Abs. Percent Error } & 108.4885 \\ \text { Theil Inequality Coef. } & 0.158935 \\ \text { Bias Proportion } \quad 0.013105 \\ \text { Variance Proportion } & 0.003168 \\ \text { Covariance Proportion } & 0.983727 \\ \text { Theil U2 Coefficient } & 0.167498 \\ \text { Symmetric MAPE } & 64.80505\end{array}$

Fig. 4 Out-of-sample forecasting of Islamic stock returns. Note The blue line refers to the Islamic stock returns forecast, while the green line represents the actual/observed Islamic stock return. (Color figure online) 


\section{(d) For quantile $75 \%$}

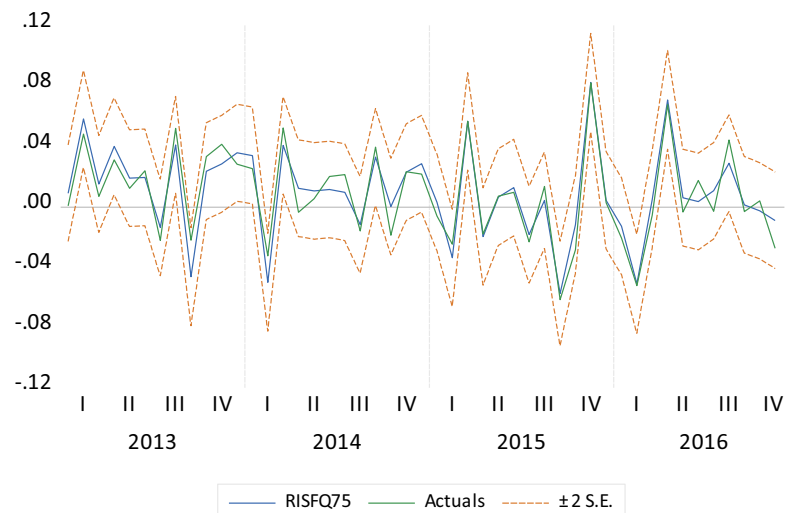

\begin{tabular}{|lc|}
\hline Forecast: RISFQ75 \\
Actual: RIS \\
Forecast sample: 2013M01 2016M12 \\
Adjusted sample: 2013M01 2016M11 \\
Included observations: 47 \\
Root Mean Squared Error & 0.010145 \\
Mean Absolute Error & 0.008557 \\
Mean Abs. Percent Error & 140.4561 \\
Theil Inequality Coef. & 0.161888 \\
Bias Proportion & 0.011796 \\
Variance Proportion & 0.007821 \\
Covariance Proportion & 0.980384 \\
Theil U2 Coefficient & 0.215035 \\
Symmetric MAPE & 69.36464 \\
\hline
\end{tabular}

(e) For quantile $97.5 \%$

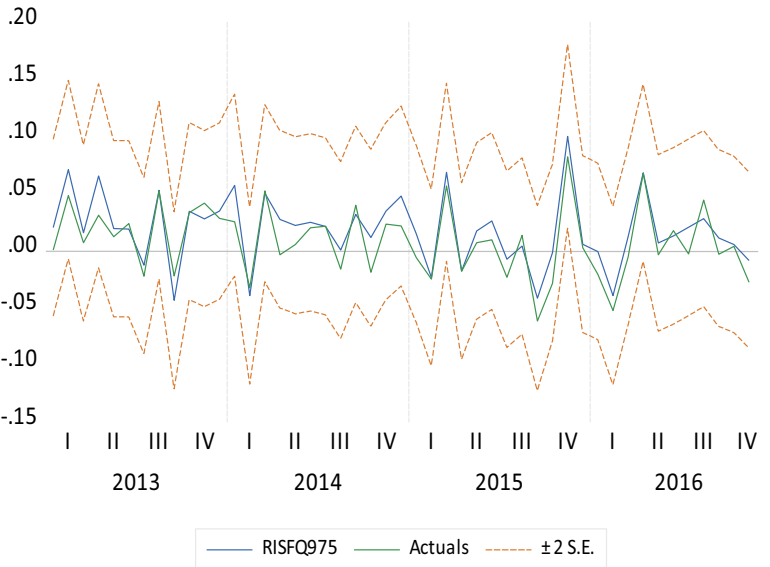

\section{Forecast: RISFQ975}

Actual: RIS

Forecast sample: 2013M01 2016M12

Adjusted sample: 2013M01 2016M11

Included observations: 47

Root Mean Squared Error $\quad 0.016343$

Mean Absolute Error 0.013417

Mean Abs. Percent Error $\quad 281.5836$

Theil Inequality Coef. 0.243692

Bias Proportion $\quad 0.353089$

Variance Proportion $\quad 0.000024$

Covariance Proportion $\quad 0.646887$

Theil U2 Coefficient $\quad 0.477382$

Symmetric MAPE $\quad 80.19493$

\section{(f) For OLS regression}

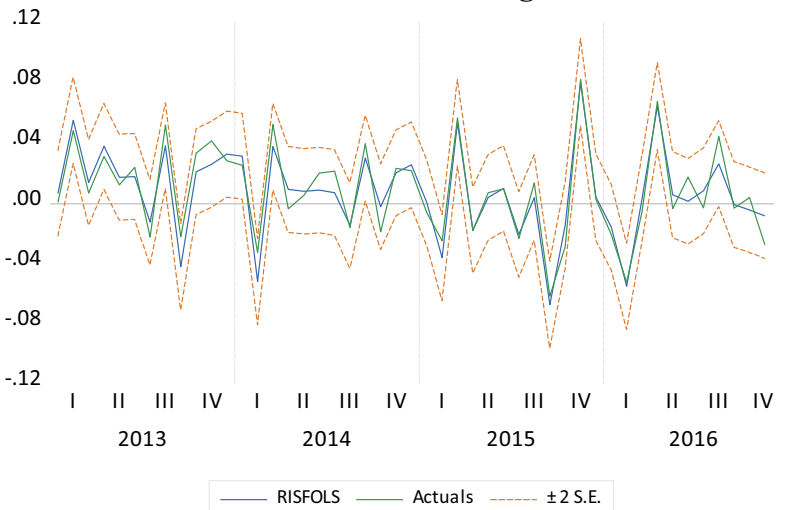

\begin{tabular}{|c|c|}
\hline \multicolumn{2}{|l|}{ Forecast: RISFOLS } \\
\hline \multicolumn{2}{|l|}{ Actual: RIS } \\
\hline \multicolumn{2}{|c|}{ Forecast sample: 2013M01 2016M12 } \\
\hline \multicolumn{2}{|c|}{ Adjusted sample: 2013M01 2016M11 } \\
\hline \multicolumn{2}{|l|}{ Included observations: 47} \\
\hline Root Mean Squared Error & 0.010049 \\
\hline \multicolumn{2}{|c|}{ Mean Absolute Error 0.008372} \\
\hline Mean Abs. Percent Error & 112.3116 \\
\hline \multicolumn{2}{|c|}{ Theil Inequality Coef. 0.162657} \\
\hline \multicolumn{2}{|c|}{ Bias Proportion $\quad 0.012122$} \\
\hline Variance Proportion & 0.014398 \\
\hline Covariance Proportion & 0.973481 \\
\hline Theil U2 Coefficient & 0.154868 \\
\hline Symmetric MAPE & 573 \\
\hline
\end{tabular}

Fig. 4 (continued) 


\section{Conclusion}

This paper investigates the relationship between investor attention and the Islamic stock market during calm and turbulent times. Our results show that while standard linear modeling fails to capture the effect of market attention, our quantile regression specification exhibits a significant effect of investor attention on the dynamics of Islamic stock returns. Interestingly, we show that the attention effect enters nonlinearity and has a time-varying impact on Islamic stock returns. Indeed, while investor attention might reduce the increase in Islamic stock returns around the low quantile, its effect is significantly more simulative around the high quantile. This suggests for higher Islamic stock returns, Islamic finance become more attractive and therefore more driven by investor's attention, as investors seek for highest benefits. Finally, we find that investor attention could help to improve the forecasting of future Islamic returns. This result is particularly interesting as the focus on investor attention, interest and sentiment may help us to better understand the evolution of Islamic stock markets and to analyze its trends.

\section{Compliance with Ethical Standards}

Conflict of interest The authors declare that they have no conflict of interest.

Ethical Approval This article does not contain any studies with human participants or animals performed by any of the authors. The paper is not under review or under revision for any other journal.

\section{References}

Akerlof, G., \& Shiller, R. (2009). Animal spirits-How human psychology drives the economy, and why it matters for global capitalism. London: Pearson.

Aloui, C., Hkiri, B., Lau, C. K. M., \& Yarovaya, L. (2016). Investors' sentiment and US Islamic and conventional indexes nexus: A time-frequency analysis. Finance Research Letters, 19, 54-59. https://doi.org/10.1016/j.frl.2016.06.002.

Bekiros, S., Gupta, R., \& Kyei, C. (2016). A nonlinear approach for predicting stock returns and volatility with the use of sentiment indices. Applied Economics, 48, 2895-2898.

Bollen, J., Mao, H., \& Zeng, X. (2011). Twitter mood predicts the stock market. Journal of Computational Science, 2(1), 1-8.

Fama, E. F., \& French, K. R. (1993). Common risk factors in the returns on stocks and bonds. Journal of Financial Economics, 33(1), 3-56. https://doi.org/10.1016/0304-405X(93)90023-5.

Fama, E. F., \& French, K. R. (2015). A five-factor asset pricing model. Journal of Financial Economics, 116(1), 1-22. https://doi.org/10.1016/j.jfineco.2014.10.010.

Ftiti, Z., \& Hadhri, S. (2019). Can economic policy uncertainty, oil prices, and investor sentiment predict Islamic stock returns? A multi-scale perspective. Pacific-Basin Finance Journal, 53, 40-55. https://doi.org/10.1016/j.pacfin.2018.09.005.

Gaunt, C. (2004). Size and book to market effects and the Fama French three factor asset pricing model: Evidence from the Australian stock market. Accounting and Finance, 44(1), $27-44$.

Jawadi, F., Jawadi, N., \& Louhichi, W. (2014). Conventional and Islamic Stock Price Performance: An Empirical Investigation. International Economics, 137, 73-87. 
Jawadi, F., Namouri, H., \& Ftiti, Z. (2017). An analysis of the effect of investor sentiment in a heterogeneous switching transition model for G7 stock markets. Journal of Economic Dynamics and Control [HCERES A, CNRS 1], 91, 469-484.

Jawadi, F., \& Sousa, R. (2014). The Relationship between Consumption and Wealth: A Quantile Regression Approach. Revue d'Economie Politique, 124, 639-652.

Khan, M. A., Ahmad, R., Azmi, A., \& Akbar, M. (2019). A new sentiment index for the islamic stock market. Investment and Analysts Journal, 48(2), 146-172.

Khmaladze, E. (1981). Martingale approach in the theory of goodness-of-it tests. Theory of Probability and its Applications, 26, 240-257.

Kim, N., Lučivjanská, K., Molnár, P., \& Villa, R. (2019). Google searches and stock market activity: Evidence from Norway. Finance Research Letters, 28, 208-220. https://doi.org/10.1016/j. frl.2018.05.003.

Koenker, R., \& Bassett, G. (1978). Regression quantiles. Econometrica, 46, 33-50.

Koenker, R., \& d'Orey, V. (1994). Remark on Alg. AAS 229: computing dual regression quantiles and regression rank scores. Applied Statistics, 43, 410-414.

Koenker, R., \& Hallock, K. F. (2001). Quantile regression. Journal of Economic Perspectives, 15(4), $143-156$.

Koenker, R., \& Xiao, Z. (2002). Inference on the quantile regression process. Econometrica, 70(4), 1583-1612.

Nguyen, C. P., Schinckus, C., \& Nguyen, T. V. H. (2019). Google search and stock returns in emerging markets. Borsa Istanbul Review, 19(4), 288-296.

Perez-Liston, D., Huerta, D., \& Haq, S. (2016). Does investor sentiment impact the returns and volatility of Islamic equities? Journal of Economics and Finance, 40(3), 421-437. https://doi.org/10.1007/ s12197-014-9290-6.

Petkova, R. (2006). Do the Famae-French factors proxy for innovations in predictive variables? The Journal of Finance, 61(2), 581-612.

Preis, T., Moat, H. S., \& Stanley, H. E. (2013). Quantifying trading behavior in financial markets using Google Trends. Scientific Reports, 3, 1684.

Shiller, R. (2015). Irrational exuberance (2nd ed.). Cambridge: Princeton University Press.

Tang, W., \& Zhu, L. (2017). How security prices respond to a surge in investor attention: Evidence from Google Search of ADRs. Global Finance Journal, 33, 38-50. https://doi.org/10.1016/j. gfj.2016.09.001.

Publisher's Note Springer Nature remains neutral with regard to jurisdictional claims in published maps and institutional affiliations. 